\title{
Haematozoan Parasites of the Lizard Ameiva ameiva (Teiidae) from Amazonian Brazil: a Preliminary Note
}

\author{
Ralph Lainson+ ${ }^{+}$, Manoel C de Souza, Constância M Franco
}

\author{
Departamento de Parasitologia, Instituto Evandro Chagas, Av. Almirante Barroso 492, 66090-000 Belém, PA, Brasil
}

Three different haematozoan parasites are described in the blood of the teiid lizard Ameiva ameiva Linn. from North Brazil: one in the monocytes and the other two in erythrocytes. The leucocytic parasite is probably a species of Lainsonia Landau, 1973 (Lankesterellidae) as suggested by the presence of sporogonic stages in the internal organs, morphology of the blood forms (sporozoites), and their survival and accumulation in macrophages of the liver. One of the erythrocytic parasites produces encapsulated, stain-resistant forms in the peripheral blood, very similar to gametocytes of Hemolivia Petit et al., 1990. The other is morphologically very different and characteristically adheres to the host-cell nucleus. None of the parasites underwent development in the mosquitoes Culex quinquefasciatus and Aedes aegypti and their behaviour in other haematophagous hosts is under investigation. Mixed infections of the parasites commonly occur and this often creates difficulties in relating the tissue stages in the internal organs to the forms seen in the blood. Concomitant infections with a Plasmodium tropiduri-like malaria parasite were seen and were sometimes extremely heavy.

Key words: Ameiva ameiva - lizards - haematozoa - haemogregarines - Lainsonia - Hemolivia - tissue stages - Brazil

Species of Ameiva (Reptilia: Squamata: Teiidae) are common terrestrial lizards, widely distributed in Central and South America and the Antilles. They frequent relatively open land, such as savannas, clearings in forests, and even the parks and gardens of built-up areas. Some 20 species are recorded (Peters \& Donoso-Barros1970, Vanzolini1986).

Carini and Rudolph (1912) gave a brief description of a haemogregarine in the erythrocytes of lizards identified as Ameiva surinamensis (syn. A. ameiva, Peters and Donoso-Barros 1970) from the state of Minas Gerais, Brazil. The parasite was named Haemogregarina ameivae, but in the absence of information on its life cycle the true nature of the parasite remains uncertain. Ayala et al. (1973) and Ayala (1975) mention the finding of "Hepatozoonlike haemogregarines" in erythrocytes of A. ameiva from the Caribbean island of Providencia and Eastern Colombia, and Telford (1977) recorded the presence of a haemogregarine in this lizard in Panama, but did not indicate the nature of the host cell.

In a search for Plasmodium species in blood films from A. ameiva during the period 1966-1992, we noted the frequent presence of three morphologically different haematozoan parasites: one in monocytes and the other two in erythrocytes. At that time examination was restricted to blood films, but more recently we have made a search for developmental stages of the parasites in the viscera of other specimens of this lizard. This preliminary note gives a light microscope description of the blood forms, and a

Financial support: Wellcome Trust, London, grant 066445 ${ }^{+}$Corresponding author. Fax:+ 55-91-226.1284. E-mail: ralphlainson@iec.pa.gov.br

Received 16 June 2003

Accepted 22 September 2003 number of tissue stages seen in the viscera which offer an indication regarding the taxonomy of two of the parasites.

\section{MATERIALS AND METHODS}

During the period 1992-2003 we examined 206 adult and juvenile A. ameiva from the vicinity of Capanema, state of Pará, where the infection-rate for haematozoa was particularly high. Blood was obtained by clipping a claw or the tip of the tail and, when this failed, from the orbital sinus with a finely drawn-out glass pipette. Thin blood films, fixed in absolute methyl alcohol, were stained for 60-80 min by Giemsa's method. Lizards apparently harbouring only one of the three parasites were selected for autopsy and pieces of liver, spleen, lung, and kidney were crushed between glass slides and coverslips and examined for tissue stages: dab smears were fixed and stained as for blood films and tissues were fixed in neutral formol-saline for histology. Photomicrographs were prepared with a Zeiss "Photomicroscope III" and Kodak TMX 100 film. Measurements are given in $\mu \mathrm{m}$, with the number of parasites measured (n). Mosquitoes fed on infected lizards were from laboratory colonies of Culex quinquefasciatus and Aedes aegypti.

\section{RESULTS}

Of the 206 A. ameiva examined, blood films of 82 $(39.8 \%)$ were apparently devoid of haematozoa. The parasite of monocytes was detected in $86(41.7 \%)$, and those of the erythrocytes in $16(7.8 \%)$. Mixed infections were noted in $22(10.7 \%)$. One lizard showed a remarkable infection with the parasite of monocytes, the two in erythrocytes and a Plasmodium tropiduri-like parasite.

The leucocytic haematozoon - In the peripheral blood the parasites appear as smoothly ovoid bodies averaging 9.7 x 6.0 (7.4-11.8 x $4.4-7.4), \mathrm{n}=50$ (Fig. 1). A close inspection, however, shows that they are really slim, elongated organisms that are doubled up on themselves, 
frequently giving the false impression that the nucleus is situated at one end of the parasite (Fig. 2). The cytoplasm stains a greyish-blue and is bounded by a reddish staining membrane: dividing forms were not seen in the peripheral blood. The host-cell nucleus becomes considerably flattened by the parasite, and numerous granules may appear in its cytoplasm (Fig. 1): double infection of cells was occasionally seen. No development of the parasite took place in either $C$. quinquefasciatus or Ae. aegypti.

Tissue stages - Infected lizards showed accumulations of the blood forms in both pigmented and non-pigmented macrophages of the liver, sometimes with 4 or 5 parasites in a single cell (Fig. 3). Developing microgametocytes were seen in the liver and spleen smears of some infected lizards: they measured about $14 \times 10$ and contained up to 50 or more small, irregular and densely stained nuclei (Fig. 4). In addition, some lung and liver smears showed small, highly vacuolated parasites of approximately $10 \times 9$ and with a small number of nuclei (Figs 5,6). These forms possibly represent developing oocysts.

The erythrocytic haematozoon, type 1: blood forms The smallest forms (Fig. 7) measure approximately $5 \times 3$, with the cytoplasm staining poorly, or not at all, and the nucleus appearing as a solid, intensely staining mass, usually occupying a central position. Older parasites average $6.8 \times 4.0(5.2-8.9 \times 3-4.4), \mathrm{n}=20$ : they do not adhere to the host cell nucleus, which is visibly unchanged but usually pushed to one side or extremity of the host cell. The nucleus of the parasite is usually in the form of a reticulum stretching across the width of the organism: rare dividing intra-erythrocytic forms were seen in liver smears (Fig. 7).

There is a gradual conversion of the larger, undivided parasites into ovoid bodies measuring $8 \times 4(n=20)$, with rounded ends and an almost colourless, cystic appearance (Fig. 8) Nuclear material of these is seen with difficulty or not at all, due to an investing capsule which inhibits entry of the stain. Host cells are not notably enlarged or deformed. No parasites could be detected in mosquitoes fed on infected lizards.

Tissue stages - Macrophages containing developing or mature schizonts producing up to 20 ovoid merozoites with a bulky, densely staining nucleus and a virtually colourless cytoplasm were very abundant in the liver smears of some lizards with this parasite (Fig. 9). We feel that the parasites in the erythrocytes originate from these merozoites, which closely resemble the young erythrocytic stages. In heavily infected lizards, the encapsulated blood forms were frequently seen in macrophages of the liver, sometimes apparently unharmed and sometimes seemingly undergoing lysis.

The erythrocytic haematozoon, type 2 - Comparing this parasite with the illustrations of $H$. ameivae (Carini \& Rudolph 1912), we have little doubt that we are dealing with the same parasite. It is readily recognised by its constant adhesion to the host cell nucleus, so that very frequently only its two extremities are visible (Fig. 10) It is a slim and elongated parasite, measuring $13.1 \times 3.0(11.1$ $x 3.0-14.8 \times 3.0) n=50$, and with a nucleus of solid and dense appearance, located at its curved extremity. No encapsulated forms similar to the other erythrocytic parasite were seen. The infected cells tend to lose their colour and distinct outline, and there may be deformation of their nucleus. No development was detected in mosquitoes fed on infected lizards.

Concomitant infections of $A$. ameiva with a $P$. tropiduri-like malaria parasite were very common and sometimes extremely heavy.

Unidentified tissue stages - In spleen smears from many autopsied lizards, single ovoid, and uninucleate parasites of $9 \times 5(n=20)$ were seen in the monocytes, sometimes in extremely large numbers (Fig. 11). In addition, fresh squash preparations and stained smears of liver and lung often revealed abundant schizonts, and cysts containing one or two cystozoites (Figs 12-16). The schizonts were frequently of two types: one with a small number of large merozoites, and the other with many smaller merozoites.

\section{DISCUSSION}

The leucocytic haematozoon - The presence of sporogonic stages in the internal organs and the accumulation of blood forms (sporozoites) in the visceral macrophages are characteristics of parasites within the family Lankesterellidae. Landau et al. (1974) consider this family to contain three genera, all of which undergo their entire life-cycle in their vertebrate hosts and produce transient oocysts which soon rupture to release the sporozoites: these then enter and circulate in the blood cells, and also accumulate and persist, in a latent fashion, in the reticulo-endothelial cells of the internal organs. Schellackia spp. develop in the gut epithelial cells and the lamina propria, whereas both Lankesterella and Lainsonia develop in viscera such as the liver, lung, kidney, and spleen. Lankesterella oocysts contain many naked sporozoites, while the oocyst of Lainsonia species contains only 8 . Although our knowledge of the sporogony of the leucocytic parasite of Ameiva is still incomplete, our observations, so far, lead us to suspect that this parasite is a species of Lainsonia Landau, 1973. It is of interest that Lainsonia legeri Landau et al. 1974 was described in a related teiid lizard, Tupinambus nigropunctatus, also from Belém.

The erythrocytic haematozoon, type 1 - The presence of encapsulated, stain-resistant parasites in the erythrocytes suggests that this parasite might be a species of Hemolivia Petit et al. 1990. Karyolysus Labbé, 1894 produces similar stages but is known only in Old World Lacerta lizards. In the tick vectors, Amblyomma spp., Hemolivia produces sporokinetes which develop into sporocysts, containing sporozoites, in the same tick: Karyolysus produces sporokinetes in the mite host, but these only develop into sporocysts in the infected mite's progeny. The presence of intra-erythrocytic dividing forms (Fig. 7) and monozoic cysts (Fig. 12) in the lizards is consistent with the life-cycle of Hemolivia and considered not to occur in infections with Karyolysus (Petit et al. 1990).

The type species of Hemolivia, H. stellata, was described in the toad Bufo marinus, from Belém, Brazil, and two additional species have since been described: H. mauritanica (Michel 1973) Landau \& Paperna, 1997 


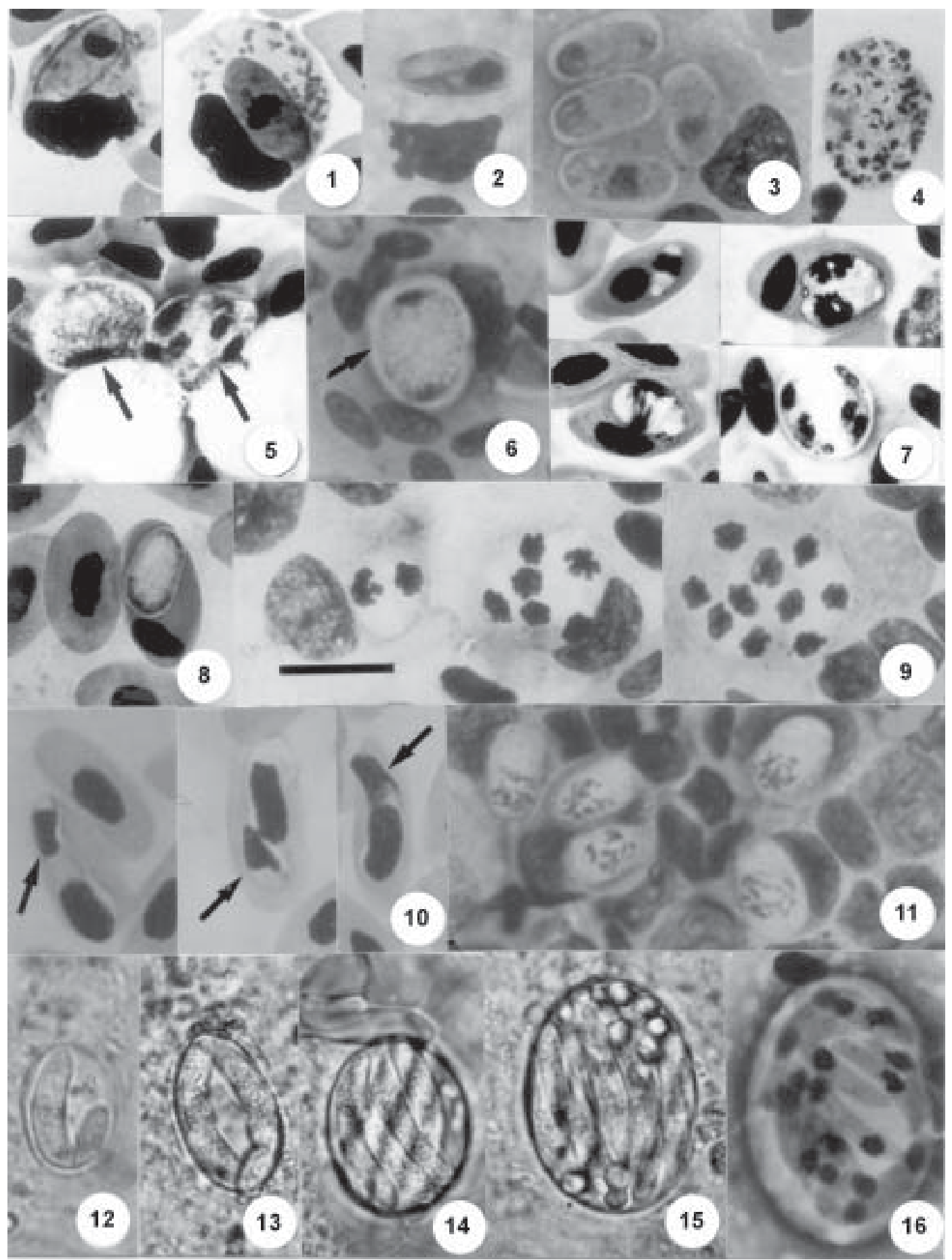

Haematozoa of the lizard Ameiva ameiva. Figs 1-6. A probable Lainsonia sp. Fig. 1-2: parasites (sporozoites?) in monocytes of the peripheral blood, showing the investing membrane, development of granules in the host cell cytoplasm, and the doubled-up nature of the parasite. Fig. 3: accumulation of the blood forms in a macrophage of a liver smear. Fig. 4: developing microgametocyte in the same smear. Figs 5-6: lung smear showing highly vacuolated parasites (arrowed) with 1, 2 and 6 nuclei, possibly representing developing oocysts. Figs 7-9: the type 1 erythrocytic haematozoon (possibly a Hemolivia sp.). Fig 7: erythrocytes of the peripheral blood containing a very young form, a larger parasite which is probably an immature gametocyte, and a bi-nucleate form: the multinucleate parasite, seemingly in an erythrocyte, is from a liver smear. Fig. 8: a mature, encapsulated parasite (gametocyte?) in the peripheral blood. Fig 9: developing schizonts in macrophages of the liver. Fig. 10: second type of intra-erythrocytic haematozoon (arrowed): note its adherance to the host cell nucleus and deformation of the erythrocyte. Figs 11-16: unidentified parasites commonly encountered in A. ameiva. Fig. 11: parasites in monocytes of spleen smears. Figs 12-15: living monozoic and dizoic cysts, and schizonts, as seen in squash preparations of liver and lung. Fig. 16: a schizont as seen in a stained liver smear. Bar in Fig. $9=10 \mu \mathrm{m}$ and applies to all other Figs. 
from tortoises, and H. mariae Smallridge \& Paperna, 1997 from Australian lizards. If the parasite of A. ameiva is a species of Hemolivia the possibility of it being conspecific with $H$. stellata must be considered, although this seems very unlikely considering the wide difference of hosts. A. ameiva and Bufo marinus do share the same habitat, however, and we have found the tick A. rotondatum on A. ameiva.

The erythrocytic haematozoon, type 2 - The failure of this parasite to develop in mosquitoes suggests that these are unsuitable hosts and its behaviour in other haematophagous hosts and development in the lizard are under further study. It is likely that some of the schizonts shown in Figs 14-16 belong to this organism.

Unidentified tissue stages - It is likely that the forms frequently seen in monocytes of the spleen smears of Ameiva (Fig. 11) are part of the life-cycle of the leucocytic haematozoon, as suggested by their joint presence in most autopsied lizards. It is of interest that they are strikingly similar to parasites the senior author described in the spleen of birds infected with Atoxoplasma, a parasite he considers to also be a lankesterellid (Lainson 1959). The stock-piling of extra-erythrocytic merozoites in reticulo-endothelial cells of the internal organs is a feature of some haematozoa, and has been considered to be a mechanism providing latent ("sleeping") forms in conditions unfavourable for the two-host life-cycle (Beyer \& Sidorenko 1984).

The schizonts and cysts illustrated in Figs 12-16 quite possibly belong to one or another of the three parasites described here, but there is the complicating fact that such stages are also characteristic of many Hepatozoon species. They are, therefore, commonly seen in the viscera of many species of lizards and amphibians which serve as reservoirs of these parasites for predators such as snakes and crocodilians (Landau et al. 1972, Lainson et al. 2003).

In conclusion, mixed infections create problems in relating tissue stages to blood forms, and their detection can be made difficult when parasitaemias of one or another of the parasites are very low. For this reason the number of mixed infections in our lizards was probably higher than the given $10.7 \%$. It must further be stressed that, in the inicial phase of infection, tissue stages of haematozoa may be found in the internal organs before the parasites invade cells of the peripheral blood. Development of the three haematozoa of $A$. ameiva in experimentally infected, putative vectors will doubtless provide more conclusive taxonomic criteria. The $P$. tropiduri-like parasite is to be described in a separate publication.

\section{REFERENCES}

Ayala SC 1975. Malaria and hemogregarines from lizards of the Western Caribbean Islands of San Andrés and Providencia. Rev Inst Med Trop São Paulo 17: 218-224.

Ayala SC, D'Alessandro A, Mackenzie R, Angel D 1973. Hemoparasite infections in 830 wild animals from the eastern llanos of Colombia. J Parasitol 59: 52-59.

Beyer TV, Sidorenko NV 1984. Karyolysus sp. (Haemogregarinidae, Adeleida, Apicomplexa): host-parasite relationships of persisting stages. J Protozool 31: 513-517.

Carini A, Rudolph M 1912. Sur quelques hématozoaires de lézards au Brésil. Bull Soc Pathol Exot 5: 592-595.

Lainson R 1959. Atoxoplasma Garnham, 1950, as a synonym for Lankesterella Labbé, 1899. Its life cycle in the English sparrow (Passer domesticus domesticus, Linn.). J Protozool 6: 360-371.

Lainson R, Paperna I, Naiff RD 2003. Development of Hepatozoon caimani (Carini, 1909) Pessoa, De Biasi \& De Souza, 1972 in the caiman Caiman c. crocodilus, the frog Rana catesbeiana, and the mosquito Culex fatigans. Mem Inst Oswaldo Cruz 98: 103-113.

Landau I 1973. Diversité des mécanismes assurant la pérennité de l'infection chez lês sporozoaires coccidiomorphes. Mém Mus Nat Hist Nat Série A, Zoologie 77, 62 pp.

Landau I, Paperna I 1997. The assignment of Hepatozoon mauriticum, a tick-transmitted parasite of tortoises, to the genus Hemolivia. Parasite 4: 365-367.

Landau I, Michel JC, Chabaud AG 1972. Cycle biologique d'Hepatozoon domerguei; discussion sur les caractères fondamentaux d'un cycle de Coccidie. Z Parasitenk 38: 250-270.

Landau I, Lainson R, Boulard Y, Shaw JJ 1974. Transmission au laboratoire et description de l'hémogrégarine Lainsonia legeri n. sp. (Lankesterellidae) parasite de lézards Brésiliens. Ann Parasitol Hum Comp 49: 253-263.

Petit G, Landau I, Baccam D, Lainson R 1990. Description et cycle biologique d'Hemolivia stellata n.g., n.sp., hémogrégarine de crapauds Brésiliens. Ann Parasitol Hum Comp 65: 3-15.

Peters JA, Donoso-Barros R 1970. Catalogue of the Neotropical Squamata: Part II Lizards and Amphisbaenians, Bulletin 297, Smithsonian Institution, US National Museum, Washington, $293 \mathrm{pp}$.

Smallridge C, Paperna I 1997. The tick-transmitted haemogregarinid of the Australian sleepy lizard Tiliqua rugosa belongs to the genus Hemolivia. Parasite 4: 359-363.

Telford SR 1977. The distribution, incidence and general ecology of saurian malaria in Middle America. Int J Parasitol 7: 299-314.

Vanzolini PE 1986. Addenda and corrigenda to the catalogue of Neotropical Squamata. Addenda and corrigenda to Part II. Lizards and Amphisbaenia. Smithson Herpetol Inf Serv 70: $1-25$. 